\title{
APPROACHES TO THE CREATION OF MULTIBODY MODELS OF THE VVER 1000 NUCLEAR REACTOR CONTROL ASSEMBLY
}

\author{
Pavel Polach $^{1,2}$, and Michal Hajžman ${ }^{2}$ \\ ${ }^{1}$ Section of Materials and Mechanical Engineering Research, Research and Testing Institute Plzeň \\ Tylova 1581/46, CZ-301 00 Plzen, Czech Republic \\ e-mail: polach@vzuplzen.cz \\ ${ }^{1,2}$ Faculty of Applied Sciences, University of West Bohemia \\ Univerzitní 8, CZ-306 14 Plzeň, Czech Republic \\ ppolach@ntis.zcu.cz, mhajzman@kme.zcu.cz
}

Keywords: Nuclear Reactor, Control Assembly, Multibody Model, Drop, Contact.

\begin{abstract}
Multibody systems modelling and analysis are efficient tools utilizable in general tasks of nonlinear dynamics. One of the branches suitable for the application of multibody approaches is the modelling of nonlinear motion and dynamical analysis in nuclear engineering. The motion of important parts of nuclear reactors called control assemblies has to be analyzed. The purpose of these control systems is to control the power of a nuclear reactor and possibly to stop the reaction in case of an emergency state. With respect to different types of nuclear reactors, different control systems composed of various mechanical parts and transmissions can be distinguished. Generally, they can be simplified to the typical problem of a long thin rod moving through guide tubes and driven by a motor. Then the modelling approach depends on the chosen mode of operation, which can be operation (regulation) under normal conditions or a certain emergency state. The paper is focused on the control assembly of the VVER 1000 nuclear reactor. The VVER 1000 reactor is a pressurized water-cooled and water-moderated reactor consisting of a reactor pressure vessel with an interior structure and a reactor upper block with 61 control assembly drives. Under the vessel head with nozzles of the control assembly drives there is a block of protective tubes, which is above the core with 163 fuel assemblies. A moveable part of the control assembly, i.e. a rod control cluster assembly (this part is the necessary condition for stopping the nuclear reaction), is composed of a suspension bar, a spider and 18 long thin absorber rods. Two modular spatial multibody models of the LKP-M/3 control assembly of the VVER 1000 nuclear reactor were created in the alaska simulation tool and they differ in their kinematic scheme and in the number of contact positions. Both models are meant for the simulations of the control assembly moving parts drop. The first one is intended for the simulations of the rod control cluster assembly drop during the seismic event, where the total time of the drop is the significant measured and computed quantity, and the second one for investigating limit curves of deformations of fuel assembly guide tubes, at which the absorber rods still reach the lower part of the core.
\end{abstract}




\section{INTRODUCTION}

Multibody systems modelling and analysis are efficient tools utilizable in general tasks of nonlinear dynamics. They are used for solving many different mechanical problems in various branches of industry. Multibody approaches are based on the concepts of classical mechanics with different complicated couplings and applied force effects. They are useful due to their ability to handle complex systems of bodies with nonlinear behaviour and they can be applied in different multidisciplinary applications.

One of the branches suitable for the application of multibody approaches is the modelling of nonlinear motion and dynamical analysis in nuclear engineering. Besides the necessary seismic analyses of reactor buildings and structures, which belong rather to structural dynamics, the motion of important parts of nuclear reactors called control assemblies has to be analyzed [1]. The purpose of these control systems is to control the power of a nuclear reactor (i.e. to control nuclear reaction) and possibly to stop the nuclear reaction in case of a defined emergency state. With respect to different types of nuclear reactors, different control systems composed of various mechanical parts and transmissions can be distinguished [2]. Generally, they can be simplified to the typical problem of a long thin rod moving through guide tubes and driven by a motor. The influences of contacts and influences of a coolant (water) surrounding the control assembly in the nuclear reactor would be considered in the mathematical models (note: the relevant sources for their introduction are given in the following chapters). The modelling approach depends on the chosen mode of operation, which can be operation (regulation) under normal conditions or a certain emergency state, in addition.

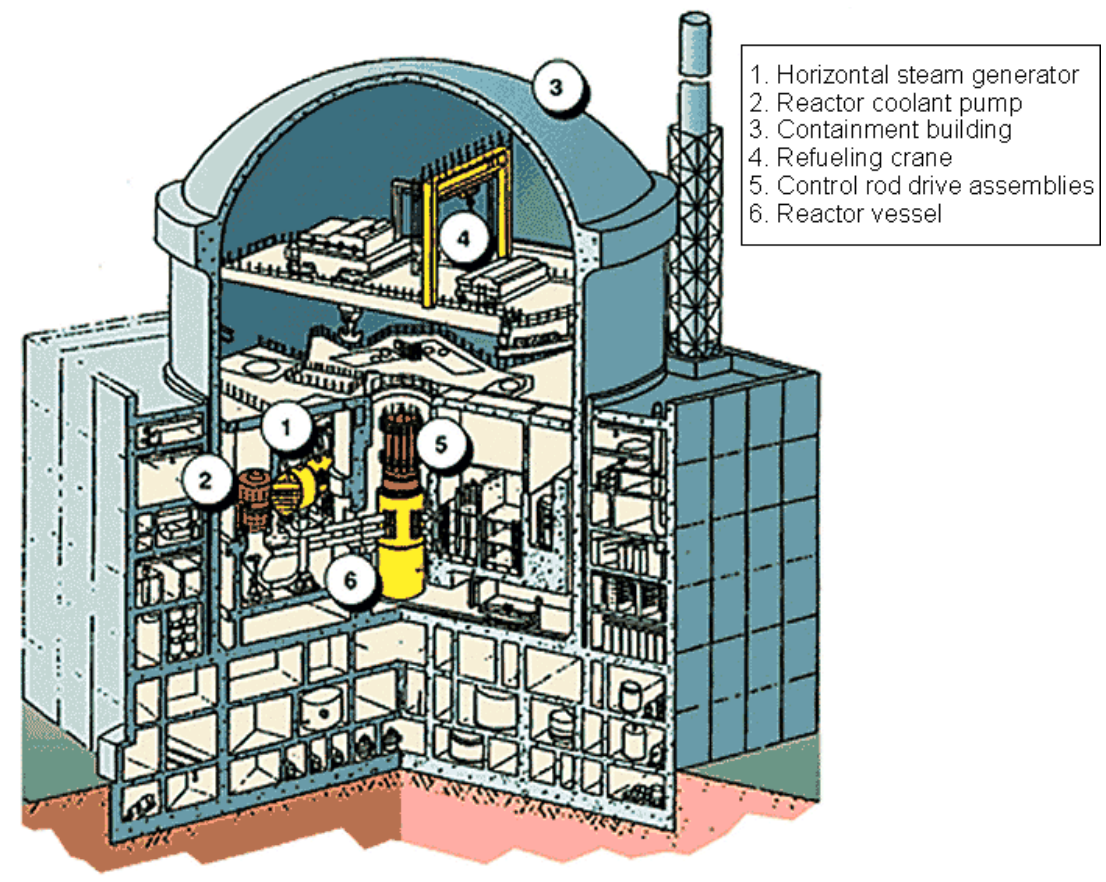

Figure 1: Scheme of the VVER 1000 plant layout.

The problem of the mechanical behaviour of a control assembly during the emergency drop is not commonly studied in available literature and therefore the investigation of this problem is a challenge. Some basic studies can be found in [1] or [3], but they are not focused on mechanical behaviour in a sufficient detail. Authors of this paper presented several approaches to modelling the flexible falling rod in $[2,4,5,6,7]$ and more detailed models of control assemblies in $[8,9,10,11]$. 
The paper is focused on multibody modelling of the control assembly of the VVER 1000 reactor. The scheme of the VVER 1000 plant layout is given in Fig. 1.

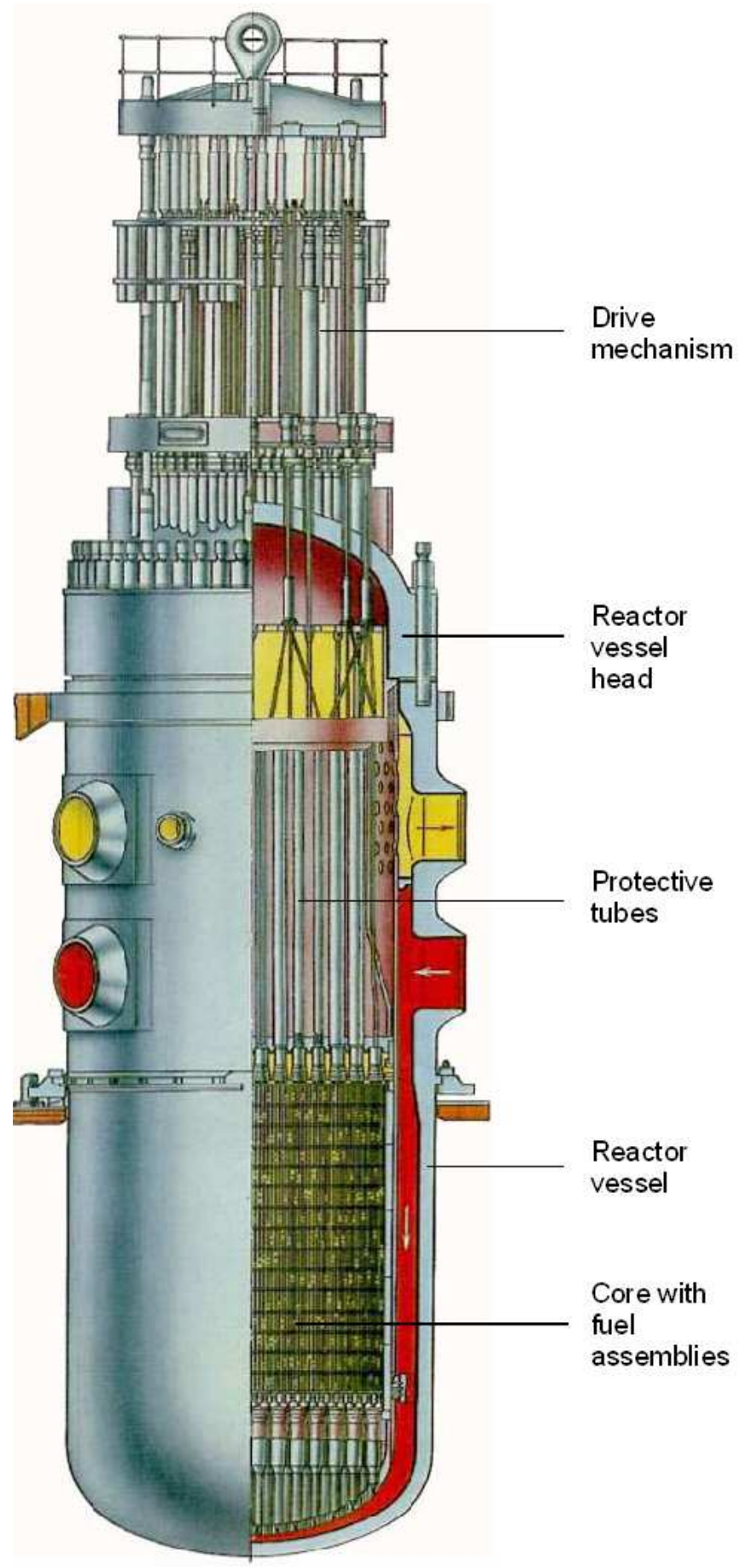

Figure 2: Scheme of the VVER 1000 reactor.

Two modular spatial multibody models of the LKP-M/3 control assembly of the VVER 1000 nuclear reactor were created in the alaska 2.3 simulation tool [12] and they differ in their kinematic scheme and in the number of contact positions. Both models are meant for the simulations of the control assembly moving parts drop. The first one is intended mainly for the simulations of the rod control cluster assembly drop during the seismic event [11], where the significant measured and computed quantity is the total time of the drop, and the second 
one for investigating limit curves of deformations of fuel assembly guide tubes [13], at which the absorber rods still reach the lower part of the core.

\section{VVER 1000 NUCLEAR REACTOR}

The VVER 1000 nuclear reactor is a pressurized water-cooled and water-moderated reactor developed in the Soviet Union and is used in many countries (e.g. the Czech Republic, the Ukraine, Bulgaria, China etc.). This reactor type is very similar to the PWR reactors produced in the USA and some west European countries.

The VVER 1000 reactor consists of a reactor pressure vessel with an interior structure and a reactor upper block with control assembly drives (see scheme in Fig. 2).

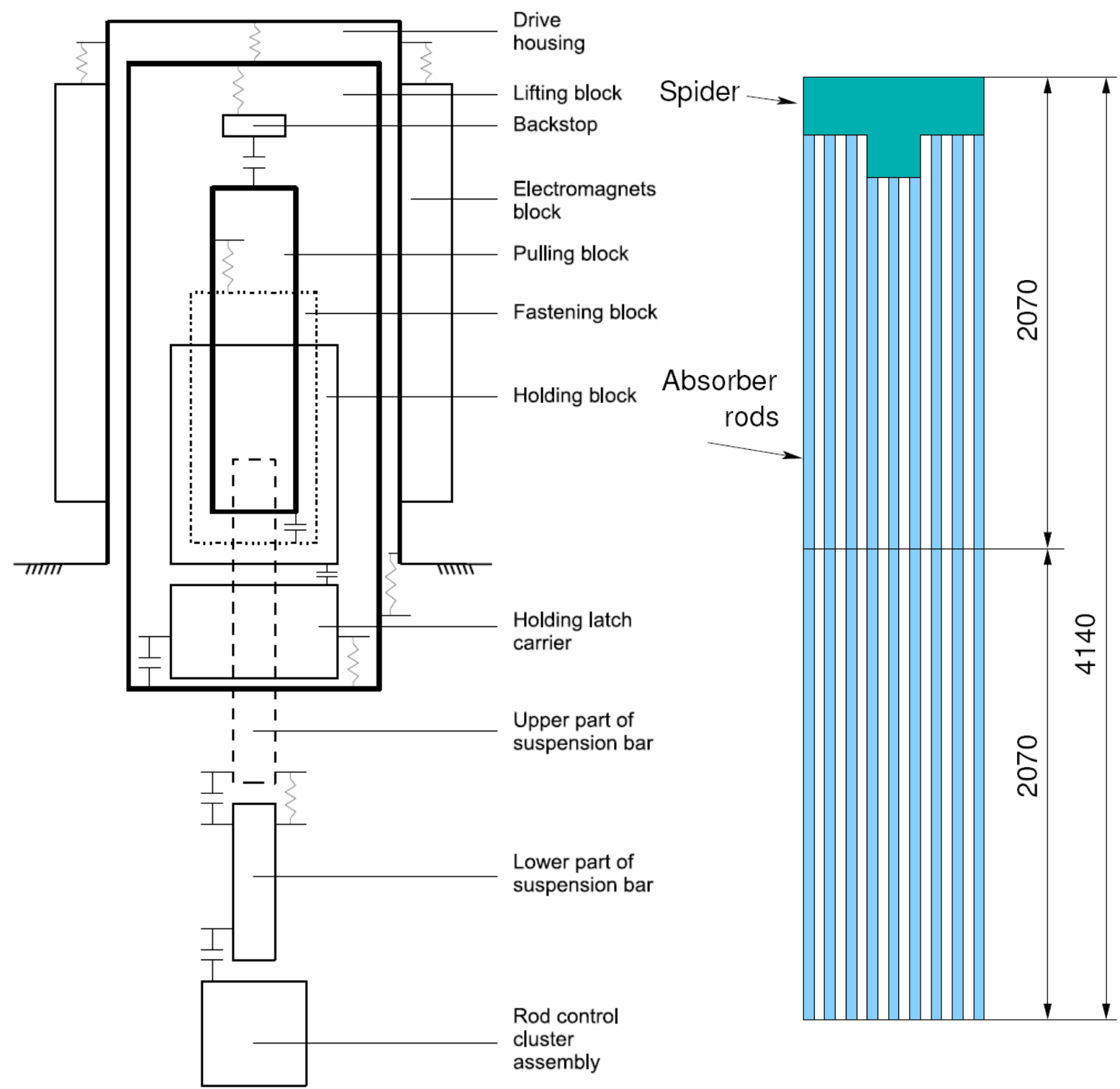

Figure 3: Scheme of the control assembly without casing (not in a real scale factor) and scheme of the rod control cluster assembly.

Under the vessel head with nozzles of the control assembly drives there is a block of protective tubes, which is above the core with fuel assemblies (so called active zone). Fuel assemblies are placed on the core support plate. 
The VVER 1000 reactor contains 163 fuel assemblies and 61 control assemblies (e.g. [14]). A moveable part of the control assembly called a rod control cluster assembly (this part is the necessary condition for the stopping of nuclear reaction), is composed of a suspension bar, a spider and 18 long thin absorber rods.

The detailed scheme of the control assembly is shown in Fig. 3. It has to be noted that the objects in this figure are not displayed in a real scale factor, especially the rod control cluster assembly. The suspension bar is divided into an upper and a lower part with a bayonet joint for connecting with a spider of the control element (i.e. the rod control cluster assembly). The suspension bar of the rod control cluster assembly is driven by a linear stepper motor, the mechanism of which is based on the usage of electro-magnets. In case of an emergency state the lifting system mechanism is set off and the rod control cluster assemblies can drop down through the protective tubes to the reactor core with fuel assemblies and stop the nuclear reaction. Other functional subsystems plotted in Fig. 3 do not influence the dynamic behaviour in the course of the studied rod control cluster assembly drop. The spider and the absorber rods of the rod control cluster assembly are schematically drawn in Fig. 3.

When the absorber rods reach the lower part of the core, they pass through the guide channel narrowing, which have the function of hydraulic shock absorbers for the stop of the rod control cluster assemblies drop.

\section{MULTIBODY MODELS OF THE CONTROL ASSEMBLY}

The spatial multibody models of the control assembly were created in the alaska 2.3 simulation tool [12] on the basis of the technical documentation and drawings provided by the control assembly producer ŠKODA JS a.s. (the Czech Republic). As it has been already mentioned, the first one is intended mainly for the simulations of the rod control cluster assembly drop during the seismic event [11] (model 1), where the significant measured and computed quantity is the total time of the drop, and the second one for investigating limit curves of deformations of fuel assembly guide tubes [13] (model 2), at which the absorber rods still reach lower part of the core. Basic summary data of both multibody models are given in Tab. 1.

\begin{tabular}{lll}
\hline & \multicolumn{2}{l}{$\begin{array}{l}\text { Model intended for simulations of the rod control cluster } \\
\text { assembly drop }\end{array}$} \\
\hline & $\begin{array}{l}\text { during the seismic } \\
\text { event (model 1) }\end{array}$ & $\begin{array}{l}\text { at considering deformations of fuel } \\
\text { assembly guide tubes (model 2) }\end{array}$ \\
\hline Number of (rigid) bodies & 23 & 22 \\
Number of kinematic joints & 23 & 22 \\
$\begin{array}{l}\text { Number of degrees of freedom } \\
\text { Number of contact points in }\end{array}$ & 56 & 45 \\
$\begin{array}{l}\text { vertical direction } \\
\begin{array}{l}\text { Number of contact positions in } \\
\text { horizontal plane }\end{array}\end{array}$ & 10 & 11 \\
\hline
\end{tabular}

Table 1: Basic summary data about multibody models of the control assembly.

Two different computational models of the control assembly were created due to the complex including of all effects influencing the rod control cluster assembly drop, which results in relatively long computational times of simulations (in the order of tens of hours). In model 1 intended mainly for the simulations of the rod control cluster assembly drop during the seismic event [11] it was necessary to consider more degrees of freedom due to introducing a 
seismic excitation and in model 2 it was necessary to consider more contact positions in a horizontal plane for investigating limit curves of deformations of fuel assembly guide tubes [13] (see Tab. 2). Dynamical aspects of the control assembly that do not influence the rod control cluster assembly drop were neglected in both computational models.

Problems of dynamical mechanical systems in nuclear engineering are of a strong multidisciplinary character. The presented multibody models are the intermediate control assembly models that should be the initial state to start the detailed study of the control assembly behaviour. The multibody models include coolant influences, impacts, contacts and, in case of model 1, seismic excitation. Not all influences and specific behaviour could be considered in detail in the models, but some aspects of the control assembly are and will be studied in more detail in future works.

\begin{tabular}{|c|c|c|c|}
\hline \multicolumn{2}{|c|}{ Contact between bodies (see Fig. 4) } & \multicolumn{2}{|c|}{ Number of contact positions } \\
\hline First body & Second body & Model 1 & Model 2 \\
\hline upper part of suspension bar & lifting block & 1 & 1 \\
\hline upper part of suspension bar & pulling block & 2 & 2 \\
\hline upper part of suspension bar & protective tube, fuel assembly & 1 & - \\
\hline upper part of suspension bar & frame & - & 1 \\
\hline cluster spider & protective tube, fuel assembly & 6 & - \\
\hline cluster spider & frame & - & 6 \\
\hline $\begin{array}{l}\text { upper parts of } 1 \text { st to } 6 \text { th } \\
\text { threes of absorber rods }\end{array}$ & protective tube, fuel assembly & 18 & - \\
\hline $\begin{array}{l}\text { upper parts of } 1 \text { st to } 6 \text { th } \\
\text { threes of absorber rods }\end{array}$ & frame & - & 24 \\
\hline $\begin{array}{l}\text { lower parts of } 1 \text { st to } 6 \text { th } \\
\text { threes of absorber rods }\end{array}$ & protective tube, fuel assembly & 12 & - \\
\hline $\begin{array}{l}\text { lower parts of } 1 \text { st to } 6 \text { th } \\
\text { threes of absorber rods }\end{array}$ & frame & - & 36 \\
\hline
\end{tabular}

Table 2: Contact positions of bodies in horizontal plane in the multibody models.

\subsection{Kinematic scheme, contact positions and seismic excitation}

Kinematic scheme of the control assembly multibody model is shown in Fig. 4, where circles represent kinematic joints (BUNC - unconstrained, PRI - prismatic in vertical axis, UNI - universal around horizontal axes) and quadrangles represent rigid bodies. In the computational model, the rigid bodies are described by their mass and inertia properties computed analytically for simple shapes or by means of the COSMOS/M software [15] based on the finite element method.

Due to virtual division of the rod control cluster assembly into thirteen rigid bodies (the purpose of this virtual division is partial considering the elastic properties of the rod control cluster assembly) certain distinguishing names of its parts were introduced (cluster spider, upper parts of the 1st to 6th threes absorber rods and lower parts of upper parts of the 1st to 6th threes absorber rods). The terminology is evident from Fig. 4 (or partly from Fig. 3 left). This modelling enables, using appropriately chosen torsional stiffnesses in the kinematic joints, to "tune" the values of the lowest natural frequencies corresponding to bending vibration modes to the natural frequencies obtained from the FEM model of the rod control cluster assembly. 
The best way of introducing the seismic excitation in the computational model is presented in $[8,9,10]$ (and in internal research report [16]), the introducing of fuel assembly guide tubes deformations is given in available publication first time ([13] is internal research report).

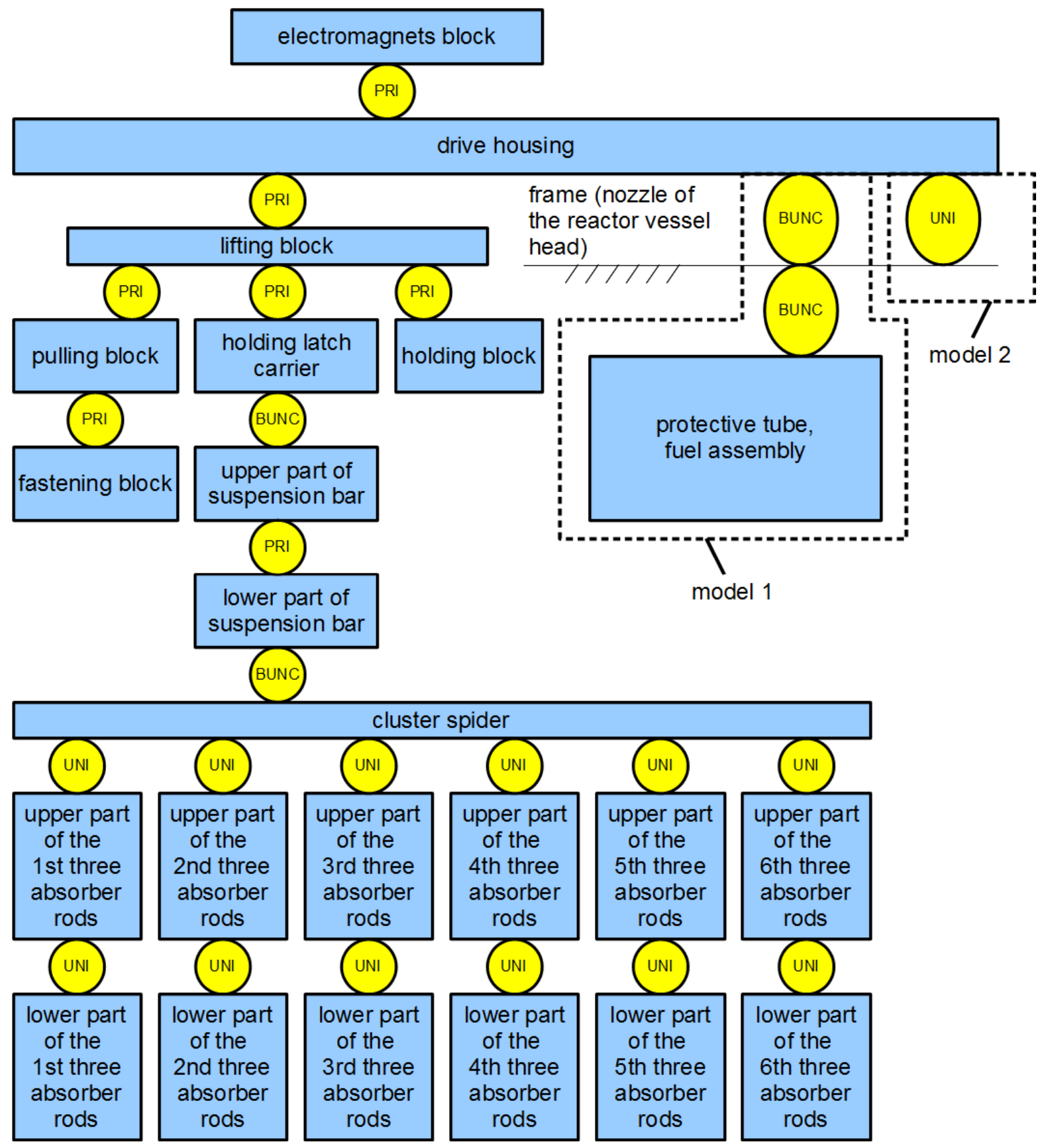

Figure 4: Kinematic scheme of the control assembly multibody models.

In multibody model 1 (i.e. model intended mainly for the simulations of the rod control cluster assembly drop during the seismic event), a special rigid body substituting interior parts in the reactor ("protective tube, fuel assembly" - see Fig. 4) is important to specify contact and impact conditions in the course of the rod control cluster assembly drop. Motion of this body and body "drive housing" are defined by seismic excitations, which are specified by time histories of the absolute displacements in three directions (see example of time history of seismic excitation in Fig. 5). In multibody model 2 (i.e. model intended for investigating limit 
curves of deformations of fuel assembly guide tubes), protective tube and fuel assembly are modelled as a part of the frame (see Fig. 4). Both considered time histories of normalized deformations of fuel assembly guide tubes are given in Fig. 6.
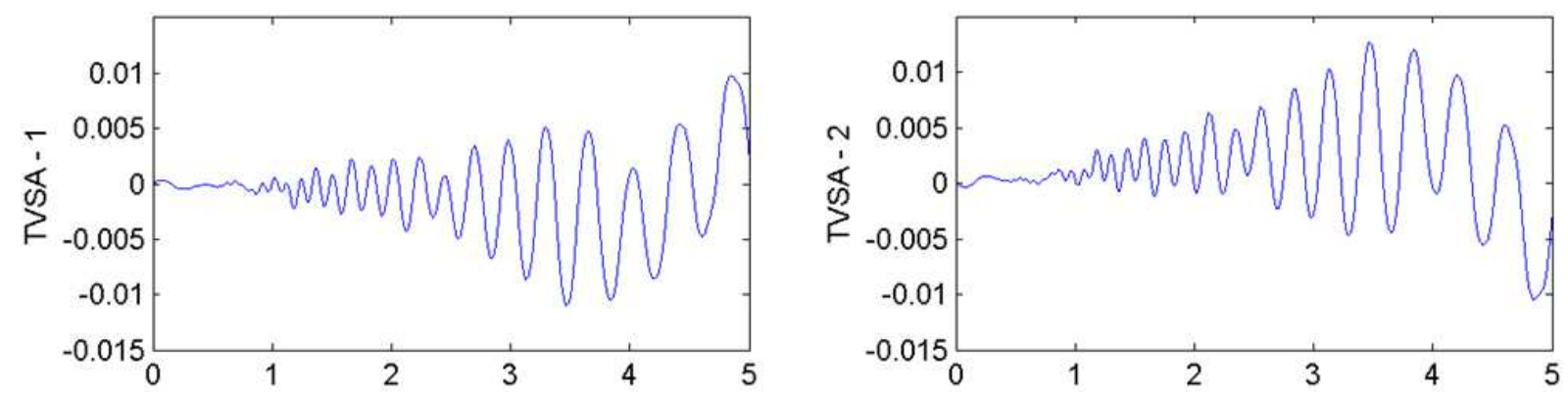

Figure 5: Time histories [s] of the absolute displacements [m] in horizontal directions in place of connection of nozzle of the reactor vessel head and drive housing during seismic event (prescribed motion of the body "drive housing").
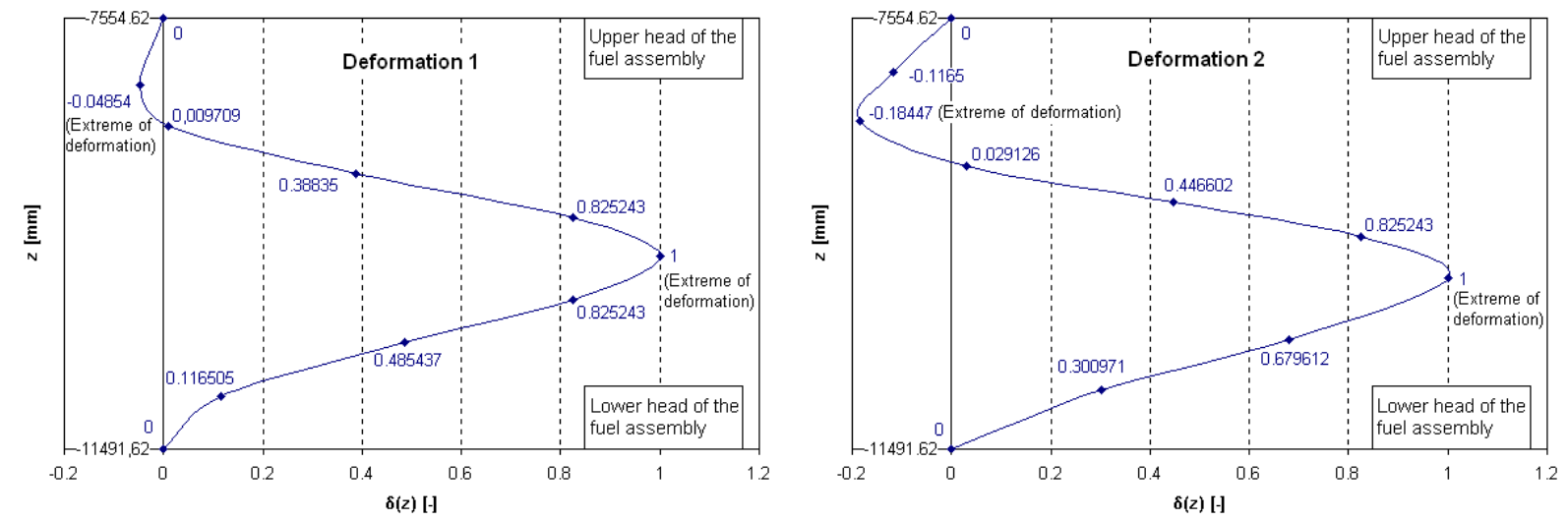

Figure 6: Normalized deformations of fuel assembly guide tubes.

\subsection{Modelling of contacts and impacts}

Possible contacts and impacts of the moving parts with adjacent structural parts inside the reactor are very important and significant aspects of the rod control cluster assembly drop modelling. Many publications studying contact problems were released, e.g. [17, 18, 19, 20]. However, it was necessary to use some simple contact-impact model of the rigid bodies applicable in the alaska 2.3 simulation tool.

The problem can be divided into two steps - the first one is the determination of the contact occurrence and contact position and the second one is the calculation of the impact force acting on the bodies. The possible bodies in contact were specified on the basis of technical documentation and drawings. Since the clearances between the falling bodies (parts of the rod control cluster assembly) and adjacent structures (protective tubes, fuel assembly guide tubes) are relatively small -1 to 7.5 millimetres - the contacts occur frequently. In all cases the contact of the body of circular cross section with the circular hole (the body moves through the hole) can occur in the multibody model. The simple geometrical consideration can decide if the contact of the body cross section boundary curves occurs or not (see Fig. 7). It holds

$$
R-\sqrt{x_{\mathrm{S}}^{2}+y_{\mathrm{S}}^{2}}-r \leq 0
$$

if the body is in contact with the adjacent structure. Coordinate system axes are designated by letters $x$ and $y, R$ is the hole radius, $r$ is the radius of the body cross section, $x_{\mathrm{S}}$ and $y_{\mathrm{S}}$ are 
horizontal displacements of the body centre. If the condition (1) is fulfilled angle $\alpha=\arctan \frac{y_{\mathrm{S}}}{x_{\mathrm{S}}}$ can be computed and relative deformation $d$ of the contact surfaces can be expressed

$$
d=R-\sqrt{x_{\mathrm{K}}^{2}+y_{\mathrm{K}}^{2}},
$$

where $x_{\mathrm{K}}=x_{\mathrm{S}}+r \cdot \cos \alpha$ and $y_{\mathrm{K}}=y_{\mathrm{S}}+r \cdot \sin \alpha$ are coordinates of contact point $\mathrm{K}$.

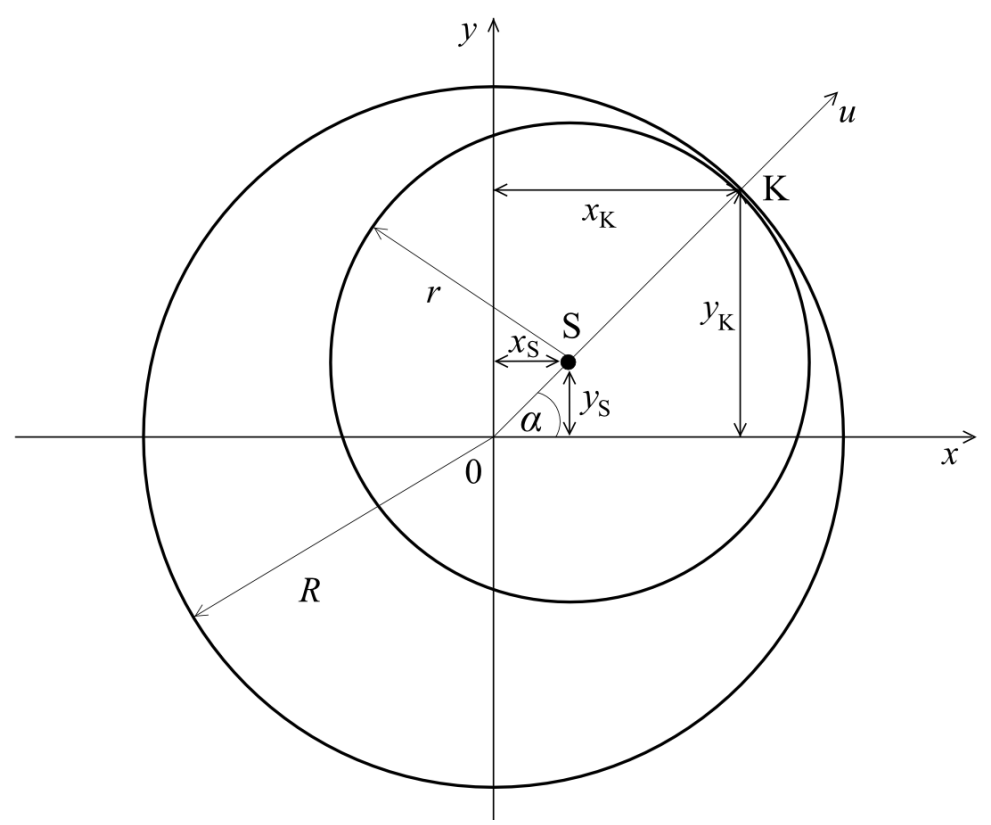

Figure 7: Contact of the body of the circular cross section moving through the circular hole.

Relative deformation $d$ is used in the impact force evaluation. E.g. the simple nonlinear Hertzian law (e.g. [21])

$$
F=k \cdot d^{n},
$$

can be used for the impact force evaluation, where $k$ is the generalized stiffness and $n$ is the constant coefficient for given materials.

The contacts are related to vertical motion and therefore the friction force

$$
F_{\mathrm{t}}=f \cdot F \text {, }
$$

where $f$ is the friction coefficient and $F$ is the impact (normal) force acting in the contact, is introduced.

The impact (normal) forces are introduced in the control assembly multibody model as the applied forces. Their instantaneous value is (instead of formula (3)) given by the bistop function [12]. After introducing axis $u$, direction of which is given by connecting point 0 (centre of the circular hole) and instantaneous position of contact point $\mathrm{K}$, and independent variable $u$ in its direction, impact (normal) force is calculated using the bistop function

$$
F=\operatorname{bistop}\left(u, \dot{u}, u_{1}, u_{2}, c, d_{\mathrm{b}}, e, b\right)= \begin{cases}-c \cdot\left(u_{1}-u\right)^{e}+\operatorname{step}\left(u, u_{1}-d_{\mathrm{b}}, b, u_{1}, 0\right) \cdot \dot{u}, & u \leq u_{1} \\ 0, & u_{1}<u<u_{2} \\ c \cdot\left(u-u_{2}\right)^{e}+\operatorname{step}\left(u, u_{2}, 0, u_{2}+d_{\mathrm{b}}, b\right) \cdot \dot{u}, & u_{2} \leq u,\end{cases}
$$


where $u$ is the independent variable, $\dot{u}$ is the first-order derivative of $u$ and $c, d_{\mathrm{b}}, e, b$ are the coefficients determining the course of the function when one of the boundary values $u_{1}=r-R$ or $u_{2}=R-r$ is exceeded.

Function step approximates a step function by evaluating a cubic polynomial, which starts at the initial ordinate value $h_{0}$ at $u=u_{0}$ and ends at the final ordinate value $h_{1}$ at $u=u_{\mathrm{E}}$

$$
\operatorname{step}\left(u, u_{0}, h_{0}, u_{\mathrm{E}}, h_{1}\right)= \begin{cases}h_{0}, & u \leq u_{0} \\ h_{0}+\left(h_{1}-h_{0}\right) \cdot\left(\frac{u-u_{0}}{u_{\mathrm{E}}-u_{0}}\right)^{2} \cdot\left(3-2 \cdot \frac{u-u_{0}}{u_{\mathrm{E}}-u_{0}}\right), & u_{0}<u<u_{\mathrm{E}} \\ h_{1}, & u_{\mathrm{E}} \leq u .\end{cases}
$$

\subsection{Influence of the coolant}

The most problematic factor in the control assembly multibody model is the influence of the pressurized water (coolant) that flows through the reactor interior structure and acts against the rod control cluster assembly motion. Like in the case of the contacts and impacts, this issue is frequently studied in the theoretical way (e.g. [22]) but the simple practical approach was necessary in case of modelling such a complex system in the alaska 2.3 simulation tool. It is evident that the main influence of coolant is the hydraulic resistance and friction slowing down the rigid body motion.

If $m_{\mathrm{F}}=\rho_{\mathrm{F}} \cdot V$ is the fluid mass pushed up by the body of volume $V=\frac{m_{\mathrm{B}}}{\rho_{\mathrm{B}}}$ static uplift pressure is respected in the corrected gravity force acting on the body

$$
G=m_{\mathrm{B}} \cdot g-m_{\mathrm{F}} \cdot g=m_{\mathrm{B}} \cdot g \cdot\left(1-\frac{\rho_{\mathrm{F}}}{\rho_{\mathrm{B}}}\right),
$$

where $m_{\mathrm{B}}$ is the body mass, $g$ is the gravity acceleration, $\rho_{\mathrm{B}}$ is the body material density and $\rho_{\mathrm{F}}$ is the coolant density.

The influence of the fluid on the horizontal vibrations is involved into the control assembly multibody model considering the hydraulic resistance force in the form (e.g. [23])

$$
F_{\mathrm{H}}=\frac{1}{2} \cdot C_{\mathrm{H}} \cdot \rho_{\mathrm{F}} \cdot S_{\mathrm{H}} \cdot v_{\mathrm{H}}^{2} \cdot
$$

The relative horizontal velocity of the body is designated $v_{\mathrm{H}}, S_{\mathrm{H}}$ is the body effective surface and $C_{\mathrm{H}}$ is the hydraulic coefficient depending on the shape of the body.

Presence of the flowing medium has essential influence on the vertical motion of the rod control cluster assembly. This effect is significant due to the falling bodies motion in the fluid filling the limited volume of the protective tubes and the fuel assemblies guide tubes and because of the fact that the fluid cannot leak out in the horizontal directions. The vertical resistance force is introduced in the control assembly multibody model using formula

$$
F_{\mathrm{V}}=\frac{1}{2} \cdot C_{\mathrm{V}} \cdot \rho_{\mathrm{F}} \cdot S_{\mathrm{V}} \cdot w^{2}
$$

The total vertical velocity of the body $w$ is the vector sum of the falling body velocity and the fluid velocity flowing against the falling body, $S_{\mathrm{v}}$ is the body effective surface and $C_{\mathrm{v}}$ is 
the hydraulic coefficient depending on the shape of the body. Due to the complexity of the cluster surface the hydraulic resistance coefficient $C_{\mathrm{V}}$ is difficult to determine accurately by the simple computation. The fact that rod control cluster assembly falls in the limited volume also makes the estimation more difficult. The way of the hydraulic resistance coefficient $C_{\mathrm{V}}$ determination is given in [16].

\section{CONCLUSIONS}

The paper presents two modular spatial multibody models of the LKP-M/3 control assembly of the VVER 1000 nuclear reactor created in the alaska 2.3 simulation tool. Both models are meant for the simulations of the control assembly moving parts drop. Model 1 is intended mainly for the simulations of the rod control cluster assembly drop during the seismic event [11], where the significant measured and computed quantity is the total time of the drop, and model 2 for investigating limit curves of deformations of fuel assembly guide tubes [13], at which the absorber rods still reach the lower part of the core. The multibody models include the influences of the fluid and the contacts and impacts of the rod control cluster assembly with the adjacent structural parts inside the reactor.

The models with the considered influences should be understood to be of the intermediate level in the framework of this topic. Various problems arising from the solution of this task will be studied in more detail in the future work. Mainly the problems of the falling body that is in contact with other bodies and interacts with fluid (coolant) in limited space have to be investigated. The rod control cluster assembly is composed of many absorber rods and consideration of their flexibility seems to be useful. Introduction to modelling the flexible rods has already been given in [2, 5, 6, 7]. The advanced modelling of flexible rods based on the absolute nodal coordinate formulation (ANCF) is given in [24].

The paper has originated in the framework of solving LG 15058 project the Ministry of Education, Youth and Sports of the Czech Republic entitled "Presidency of CEACM and related posts" and institutional support for the long-time conception development of the research institution provided by the Ministry of Industry and Trade of the Czech Republic to Research and Testing Institute Plzeň.

\section{REFERENCES}

[1] D. Bosselut, H. Andriambololona, E. Longatte, J. Pauthenet, Insertion and drop of control rod in assembly simulations and parametric analysis. Technical meeting on structural behaviour of fuel assemblies for water cooled reactors, IAEA-TECDOC-1454, Cadarache, France, November 22-26, 2004.

[2] M. Hajžman, P. Polach, Nonlinear Dynamic Analysis of Flexible Control Rods in Nuclear Reactors. The Third Asian Conference on Multibody Dynamics 2006, Tokyo, Japan, August 1-4, 2006.

[3] B. Collard, RCCA Drop Kinetics Test, Calculation and Analysis, Abnormal Friction Force Evaluation. $7^{\text {th }}$ International Conference on Nuclear Engineering, Tokyo, Japan, April 19-23, 1999.

[4] R. Bulín, M. Hajžman, P. Polach, Basic Model of a Control Assembly Drop in Nuclear Reactors. Transactions of the V̌̌S - Technical University of Ostrava, Mechanical Series, 59, 1-7, 2013. 
[5] M. Hajžman, P. Polach, Modelling of Flexible Rods Falling in Fluid with Possible Contacts. C. A. Mota Soares, J. A. C. Martins, H. C. Rodrigues, J. A. C. Ambrósio, C. A. B. Pina, C. M. Mota Soares, E. B. R. Pereira, J. Folgado eds. III European Conference on Computational Mechanics: Solids, Structures and Coupled Problems in Engineering, Lisbon, Portugal, June 5-8, 2006.

[6] M. Hajžman, P. Polach, Two Approaches to The Modelling of The Control Rods in Nuclear Reactors. The Fourth Asian Conference on Multibody Dynamics ACMD2008, Jeju, Republic of Korea, August 20-23, 2008.

[7] M. Hajžman, P. Polach, Modelling of flexible bodies in the framework of multibody systems. B. Skočilasová ed. $6^{\text {th }}$ International Conference Dynamics of Rigid and Deformable Bodies 2008, Ústí nad Labem, Czech Republic, September 17-19, 2008.

[8] M. Hajžman, P. Polach, Modelling and Seismic Response of the Control Assembly for the VVER 440/V213 Nuclear Reactor. J. M. Goicolea, J. Cuadrado, J. C. García Orden eds. ECCOMAS Thematic Conference Multibody Dynamics 2005 on Advances in Computational Multibody Dynamics, Madrid, Spain, June 21-24, 2005.

[9] M. Hajžman, P. Polach, Multibody analysis of the control assembly drop in the VVER 440/V213 nuclear reactor. J. Náprstek, C. Fischer eds. National Conference with International Participation Engineering Mechanics 2006, Svratka, Czech Republic, May 1518, 2006.

[10] M. Hajžman, P. Polach, Seismic Analysis of the Control Assembly of the IRT-200 Research Nuclear Reactor by Means of a Multibody Approach. M. Papadrakakis, D.C. Charmpis, N.D. Lagaros, Y. Tsompanakis eds. ECCOMAS Thematic Conference COMPDYN 2007 on Computational Methods in Structural Dynamics and Earthquake Engineering, Rethymno, Crete, Greece, June 13-16, 2007.

[11] P. Polach, M. Hajžman, Multibody Model of the Control Assembly of the VVER 1000 Nuclear Reactor. B. Skočilasová ed. 7th International Conference Dynamics of Rigid and Deformable Bodies, Ústí nad Labem, Czech Republic, September 9-11, 2009.

[12] P. Maißer, C.-D. Wolf, A. Keil, K. Hendel, U. Jungnickel, H. Hermsdorf, P. A. Tuan, G. Kielau, O. Enge, U. Parsche, T. Härtel, H. Freudenberg, alaska, User Manual, Version 2.3. Institute of Mechatronics, Chemnitz, Germany, 1998.

[13] P. Polach, M. Hajžman, Multibody model of the LKP-M/3 control assembly of the VVER 1000 nuclear reactor for investigating limit curves of deformations of fuel assembly guide tubes, research report VYZ 0880/06. ŠKODA VÝZKUM s.r.o., Plzeň, Czech Republic, 2006. (in Czech)

[14] V. Zeman, Z. Hlaváč, Dynamic Response of VVER 1000 Type Reactor Excited by Pressure Pulsation. Engineering Mechanics, 15, 435-446, 2008.

[15] COSMOS/M, Finite Element Analysis System, User Guide, Version 2.9. SRAC, Los Angeles, USA, 2006.

[16] P. Polach, M. Hajžman, Multibody model of the LKP-M/3 control assembly of the VVER 1000 nuclear reactor and calculation of time of the fall of the rod control cluster assembly at seismic event, research report VYZ 0755/2005. ŠKODA VÝZKUM s.r.o., Plzeň, Czech Republic, 2005. (in Czech) 
[17] M. K. Vukobratovic, V. Potkonjak, Dynamics of contact tasks in robotics. Part I: general model of robot interacting with environment. Mechanism and Machine Theory, 34, 923-942, 1999.

[18] T. Klisch, Contact Mechanics in Multibody Systems. Multibody System Dynamics, 2, 335-354, 1998.

[19] W. Schiehlen, R. Seifried, Three Approaches for Elastodynamic Contact in Multibody Systems. Multibody System Dynamics, 12, 1-16, 2004.

[20] A. Kecskeméthy, Ch. Lange, G. Grabner, Analysis of Impact Responses Using the Regularized Model Approach. EUROMECH Colloquium 397, Grenoble, France, June 30 July 2, 1999.

[21] P. Flores, J. C. Pimenta Claro, J. Ambrósio, H. M. Lankarani, C. Sony Koshy, Study of Contact-Impact Force Models in Multibody Mechanical Systems. $10^{\text {th }}$ Conference on Nonlinear Vibrations, Stability and Dynamics of Structures, Blacksburg, Virginia, USA, July 25-28, 2004.

[22] E. Feireisl, On the motion of rigid bodies in a viscous fluid. Applications of Mathematics, 47, 463-484, 2002.

[23] R. V. Giles, Fluid Mechanics and Hydraulics. McGraw-Hill, 1962.

[24] R. Bulín, M. Hajžman, P. Polach, Nonlinear dynamic analysis of a single control rod in nuclear reactors. L. Pešek ed. National Colloquium with International Participation Dynamics of Machines 2014, Prague, Czech Republic, February 4-5, 2014. 